\title{
BMJ Open Discrete time measures versus trajectories of drinking frequency across adolescence as predictors of binge drinking in young adulthood: a longitudinal investigation
}

\author{
Marie-Pierre Sylvestre (D) , ${ }^{1,2}$ Robert J Wellman, ${ }^{3}$ Marilyn N Ahun, ${ }^{1}$ \\ Geetanjali Datta, ${ }^{1,2}$ Didier Jutras-Aswad, ${ }^{2,4}$ Jennifer O Loughlin ${ }^{1,2}$
}

To cite: Sylvestre M-P, Wellman RJ, Ahun MN, et al. Discrete time measures versus trajectories of drinking frequency across adolescence as predictors of binge drinking in young adulthood: a longitudinal investigation. BMJ Open 2020;10:e035939. doi:10.1136/ bmjopen-2019-035939

- Prepublication history and additional material for this paper is available online. To view these files, please visit the journal online (http://dx.doi.org/10. 1136/bmjopen-2019-035939)

M-PS and RJW are joint first authors.

Received 22 November 2019 Revised 13 August 2020 Accepted 18 August 2020

\section{Dheck for updates}

(C) Author(s) (or their employer(s)) 2020. Re-use permitted under CC BY-NC. No commercial re-use. See rights and permissions. Published by BMJ.

For numbered affiliations see end of article.

Correspondence to Dr Marie-Pierre Sylvestre; marie-pierre.sylvestre@ umontreal.ca

\section{ABSTRACT}

Objectives We compared discrete time measures with trajectories of adolescent drinking frequency as predictors of sustained binge drinking in young adulthood.

Design Prospective longitudinal study.

Setting 10 high schools in Montréal, Canada.

Participants 1293 high-school students followed from mean (SD) age $12(0.6)$ to 24 (0.7) years.

Primary outcome measures Patterns of drinking frequency (self-reports every 3 months from ages 12 to 17) identified using group-based trajectory modelling. Sustained binge drinking was defined as binging monthly or more often at both ages 20 and 24 .

Analyses Using logistic regression, sustained binge drinking was regressed on trajectory group membership and on four discrete time measures (frequency of drinking at age 12; frequency of drinking at age 17; age at drinking onset; age at onset of drinking monthly or more often). Results We identified seven drinking trajectories: late triers $(15.2 \%)$, decreasers $(9.5 \%)$, late escalators $(10.4 \%)$, early slow escalators (16.5\%), steady drinkers (14.4\%), early rapid escalators (15.8\%) and early frequent drinkers (18.2\%). Sustained binge drinking was reported by 260 of 787 participants $(33.0 \%)$ with complete data at both ages 20 and 24. Decreasers did not differ from late triers; all other patterns were associated with higher odds of sustained binge drinking (adjusted ORs: AORs=1.4-17.0). All discrete time measures were associated with sustained binge drinking, notably frequency at age 12 (a bit to try and drinking monthly: (AORs=2.6 $(1.7 ; 3.9)$ and 2.8 $(1.3 ; 6.1)$, respectively), age of drinking onset $<13$ years $(A O R=7.6(3.0 ; 24.1))$, and any age of onset of drinking monthly or more often (AORs=5.1-8.2).

Conclusion Youth at risk of sustained binge drinking as young adults can be identified with indicators of early drinking as early as 7th grade (aged 12-13 years). Identification of easy-to-obtain indicators can facilitate screening and intervention efforts.

\section{INTRODUCTION}

Alcohol consumption is commonly initiated in adolescence. ${ }^{12}$ In 2014-2015, underage drinking was reported by $49 \%$ of Canadian
Strengths and limitations of this study

- Strengths include dense observations on alcohol use over more than a decade.

- Discrete time measures of drinking frequency were measured prospectively and compared with trajectories as predictors of sustained binge drinking in young adulthood.

- We use inverse probability weighting to account for attrition in young adulthood.

- Limitations include lack of data on binge drinking in adolescence.

- Since $42 \%$ of participants had already used alcohol by age 12 , our trajectories cannot fully capture the natural course of alcohol use.

youth including $19 \%$ of grade $7-9$ students. ${ }^{3}$ In $2016,26 \%$ of 8 th graders in the USA had tried more than a few sips of alcohol, and $11 \%$ reported being drunk at least once. ${ }^{2}$ Early alcohol use is associated with adverse outcomes in adulthood including binge (ie, heavy episodic) drinking, and young adults who binge are more likely to experience physical harm and acute and persistent health problems such as altered neurophysiological and neurocognitive function. ${ }^{4-6}$ In addition, frequent (ie, $\geq 3$ episodes in the past 2 weeks) and sustained binge drinking increases the risk of alcohol-use disorders. ${ }^{6}$ Early intervention may prevent or delay development of risky drinking and associated health problems. ${ }^{78}$ However, the US Preventive Services Task Force (USPSTF) concluded in 2013 that the current evidence is insufficient to recommend screening for alcohol misuse in adolescents, ${ }^{9}$ in part because there is no consensus on which early drinking patterns lead to excessive use or necessitate intervention. ${ }^{10}$ 
Group-based trajectory modelling is frequently used to identify adolescent drinking patterns. Over a dozen studies estimate trajectories of adolescent alcohol use and then use these trajectories to study associated risk factors and outcomes. ${ }^{11}$ Most report a consistently low use pattern including abstainers; a consistently high use pattern and a 'normative' trajectory with abstinence at younger ages and increased use in late adolescence. Higher levels of alcohol consumption in late adolescence track into young adulthood, ${ }^{11}$ and adolescents whose use is consistently high are more likely than abstainers to have alcohol use disorders in young adulthood. ${ }^{1}$

Several studies on drinking outcomes have used trajectories of binge drinking-rather than general alcohol consumption-across adolescence and early adulthood and found that compared with abstainers, individuals who engaged in higher levels of binge drinking across time were more likely to have poorer physical and mental health, to be engaged in crime and to abuse or be dependent on drugs. ${ }^{2-15}$ Although persistent binge drinking is associated with an increased risk of later health problems ${ }^{16}$ no study has examined whether alcohol-use trajectories during adolescence are associated with sustained binge drinking in adulthood.

Several knowledge gaps and methodological limitations of the literature on adolescent alcohol use inhibit translation of research findings into recommendations for intervention. First, while early onset is associated with later substance use, ${ }^{17}$ few studies report longitudinal patterns of alcohol consumption beginning in early adolescence. Second, most studies compare drinkers with non-drinkers or low-level drinkers. Because adolescent alcohol consumption is so prevalent, ${ }^{2}{ }^{3}$ distinguishing among patterns of use may be more informative for intervention than comparing drinkers and non-drinkers. But low-risk and high-risk alcohol-use patterns must be sufficiently distinct at one or more key transitions (eg, the beginning or end of high school) to identify youth who could benefit from intervention. Although trajectories are intuitively interpretable and therefore attractive, trajectory modelling has been criticised, with some arguing that trajectory groups may simply be artefacts of the statistical methods used. ${ }^{18}{ }^{19}$ Further, estimating trajectories requires that the time intervals between measurements are the same across all participants, which may not be feasible.

Assuming that collecting data at discrete time points is less complex than collecting data required to model trajectories, an alternative approach is to take snapshots of drinking at major transition points (eg, beginning of high school when children transition to larger schools with new modes of instruction and unfamiliar students; end of high school when parental monitoring or control may be waning). Age at first drink and the time point when one transitions to more frequent drinking may also relate to health outcomes. A large cross-sectional study demonstrated that age-specific cutoffs in frequency of past-year alcohol use had high sensitivity and specificity in identifying youth with diagnosable alcohol-use disorders. ${ }^{20}$
However, no study to date has compared the usefulness of discrete time measures against trajectories in predicting sustained binge drinking in young adulthood.

To address the relative usefulness of trajectory versus discrete time approaches in predicting binge drinking in young adulthood, we first describe trajectories of drinking frequency from ages 12 to 17 and present four snapshot measures of drinking assessed at potentially key transition points (ie, beginning of high school, end of high school, first report of using alcohol and first report of drinking monthly or more often). We then identify which trajectories and snapshot measures are associated with sustained binge drinking between ages 20 and 24. We investigated sustained binge drinking in young adulthood because evidence suggests that this is a risk factor for later alcohol dependence. $^{21} 22$

\section{METHODS}

\section{Participants}

Data were drawn from the Nicotine Dependence in Teens Study, a prospective longitudinal investigation of $12937 \mathrm{th}$ grade students recruited in 10 Montréal-area (Canada) high schools. ${ }^{23}$ Selected high schools included Frenchlanguage and English-language schools located in urban, suburban and rural regions and serving populations of high, moderate or low socioeconomic status. Self-report questionnaires were administered at school every 3 months for a total of 20 cycles during high school from 1999 to 2005 (mean (SD) age=12.7 (0.5) to $17.1(0.4)$ ), and mail or in-person questionnaires in 2007-2008 (cycle 21) and 2011-2012 (cycle 22) when participants were aged 20 and 24 years on average, respectively.

Parents/guardians provided informed consent at baseline and participants consented in young adulthood. This sample was comparable at inception to a provincially representative sample of 13 -year-old ${ }^{24}$ adolescents although the prevalence of alcohol use at baseline was lower $(44 \%$ vs $51 \%) .{ }^{23}$ Binge drinking at ages 20 and 24 was also lower in our sample $(66 \%)$ than in a nationally representative sample of young adults $(79 \%){ }^{3}$

\section{Patient and public involvement}

It was not appropriate or possible to involve study participants or the public in the design, conduct, reporting or dissemination plans for this analysis.

\section{Measures}

In cycles 1-20, participants were asked how often (never, a bit to try, once or a couple of times a month, once or a couple of times a week, usually every day, coded 1-5) they drank alcohol (beer, wine, liquor) in the past 3 months. The full range of frequencies was used for trajectory modelling. The intraclass correlation coefficient (ICC) for drinking frequency within schools was low $(\mathrm{ICC}=0.01)$, so the analyses did not account for school clustering.

The four discrete time measures were: (1) drinking frequency at age 12 (ie, cycle 1 at the beginning of 7 th 
grade); (2) frequency at age 17 (ie, cycle 20 at the end of high school); (3) age at drinking onset (ie, the youngest age at which participants first reported any alcohol use) and (4) age at onset of drinking monthly or more often. Drinking 1-6 times per week and drinking every day were collapsed into 'weekly drinking'. The age measures were categorised as never, $<13,13-15,>15$ years. In sensitivity analyses, we investigated the stability of the snapshot measures by considering two additional measures that pooled observations over a year, namely (5) modal frequency during 7 th grade (ie, cycles 1-4) and (6) modal frequency during 11th grade (ie, cycles 17-20 in the last year of high school). Modal frequency corresponded to the value of alcohol use most frequently reported over a year. In cases of ties (eg, when a participant reported both 'once or a couple of times a month' and 'once or a couple of times a week' two times over the year), modal frequency was set to the higher of the two alcohol use frequencies.

Participants were asked at ages 20 and 24 how often (never, less than once a month, 1-3 times per month, 1-6 times per week, every day) in the past 12 months they drank $\geq 5$ alcoholic beverages on one occasion. ${ }^{25}{ }^{26}$ Because binging every day was reported by only two participants, we collapsed the two highest categories to 1-7 times per week ('weekly'). We created a binary variable for the outcome, sustained binge drinking, where $1=$ monthly or more often at both ages 20 and 24, and $0=$ all other groups (ie, never binged, binged less than monthly at either or both age(s), binged monthly or more often at only one age). ${ }^{4}$

Descriptive data collected at baseline included mother university-educated (yes/no); language (French/other); single-parent family (yes/no); parents smoke (yes/no); friends smoke (yes/no) and depressive symptoms in past 3 months (6 items, 4-point scale). Impulsivity (7 items, 5-point scale) and novelty-seeking (9 items, 5-point scale) were assessed in cycle 14 (mean age $=15.8$ years). Online supplemental table $\mathrm{S} 1$ describes the study variables in detail.

\section{Analytical procedure}

We identified drinking frequency patterns by estimating group-based trajectory models of 2-10 trajectories using the PROC TRAJ command in SAS 9.4 for censored-normal distributions. ${ }^{27}$ We estimated models with an increasing number of trajectories until the Bayes factor, approximated by twice the change in the Bayesian Information Criterion between consecutive models, failed to decrease. We identified the number of trajectories by choosing the model that minimised the Bayes factor among models in which all trajectory groups had at least $5 \%$ of the sample. Each participant was assigned a posterior probability of belonging to each trajectory group and then assigned to the single group for which she/he had the highest probability. An average posterior probability (APP) $\geq 0.7$ indicated satisfactory classification. ${ }^{27}$ In sensitivity analyses we used estimated trajectories and the probability of non-random dropout from each group. ${ }^{28}$ The probability of loss to follow-up was modelled as a function of age, sex, mother university-educated and single-parent family. The pattern of results was similar, and therefore we report results from dropout models.

We contrasted sample characteristics across trajectory groups using analysis of variance (ANOVA) for normally distributed continuous variables, Kruskall-Wallis tests for non-normally distributed variables and $\chi^{2}$ tests for categorical variables. Post-hoc tests (ie, Tukey-Kramer procedure for ANOVA and Kruskall-Wallis; Holm procedure for $\chi^{2}$ ) identified trajectory pairs with different features while accounting for multiple testing and maintaining the family-wise error rate at $5 \%$.

We used logistic regression models to test associations between sustained binge drinking and trajectory group membership and each of the four discrete time variables, adjusting for the loss of participants during high school using the inverse probability of attrition weights based on age, sex, mother university-educated and singleparent family. Covariates in the logistic regression models included contextual factors associated with early and binge drinking (ie, mother university-educated, language, single-parent family, parents smoke, friends smoke). ${ }^{1629} 30$ We replaced missing values for these variables at baseline with the earliest non-missing value within year 1 of the study (ie, cycles 2-4). Online supplemental table S2 shows missingness patterns for these variables. Participants for whom missing values could not be replaced were excluded from these analyses. Given sex differences in alcohol use, we also adjusted for sex. Testing whether sex modified the association between alcohol use and binge drinking was performed using interaction terms between sex and alcohol use variables that were examined jointly using likelihood ratio tests. ${ }^{31}$ We do not report sex-specific analyses because none of the tests for effect modification were statistically significant.

To account for the uncertainty in classifying individuals into trajectory groups, we included weights proportional to the individual posterior probabilities of trajectory membership in the logistic models and computed $95 \%$ confidence bands using bootstrap. ${ }^{32}$ Hosmer-Lemeshow goodness of fit tests were performed on adjusted logistic models. We assessed the predictive value of each alcohol use variable by evaluating the additional predictive information provided by the inclusion of the alcohol variable in the model that only contains covariates. ${ }^{33} 34$ The additional predictive information was computed as 1 - $\left(L R_{A}\right)$ $L R_{A B}$ ), where $\mathrm{LR}_{\mathrm{A}}$ and $\mathrm{LR}_{\mathrm{AB}}$ are likelihood ratio $\chi^{2}$ statistics corresponding respectively to the model containing covariates only and the model with covariates and the alcohol use variable.

\section{RESULTS}

\section{Trajectory group analyses}

The seven-group trajectory model (figure 1) was selected (see online supplemental table S3 for fit statistics of all models). 'Late triers' ( $15.2 \%$ of participants; APP=0.85) 


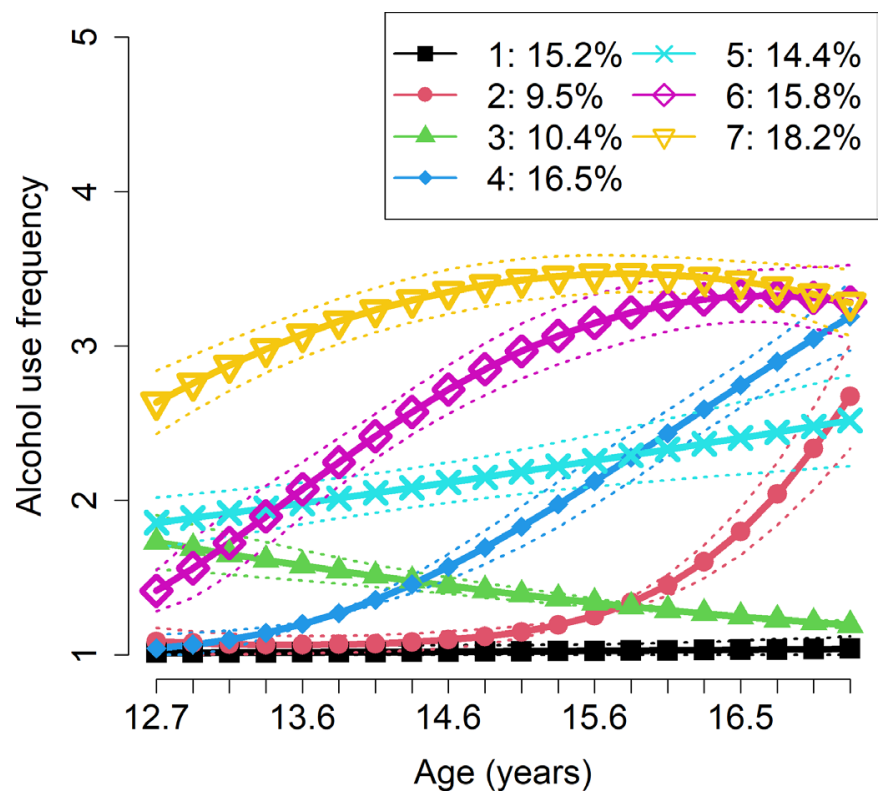

Figure 1 Group-based trajectories of adolescent alcohol consumption frequency, Nicotine Dependence in Teens (1999-2011). Alcohol consumption frequency in the past 3 months was coded as $1=$ "never'; $2=$ "a bit to try'; $3=$ "' $1-2$ times a month'; 4=‘1-2 times a week’; 5='usually every day'.

began drinking infrequently toward the end of follow-up; 'decreasers' (9.5\% of participants; APP=0.87) decreased frequency of alcohol use over time and 'late escalators' ( $10.4 \%$ of participants; APP $=0.85)$ abstained at younger ages and started drinking more frequently at age 15 . There were two early escalating groups including a rapid group ('early rapid escalators'; $15.8 \%$; $\mathrm{APP}=0.76$ ) and a slow group ('early slow escalators'; $16.5 \%$; APP=0.83). Finally, $14.4 \%$ of participants maintained a relatively stable frequency of alcohol use over time ('steady drinkers'; $\mathrm{APP}=0.77$ ), and the largest group, 'early frequent drinkers' (18.2\%; APP=0.86) drank once or a couple of times a month at baseline, increased consumption over 3 years and then plateaued at age 15 . The trajectories of early frequent drinkers, early rapid escalators and steady drinkers converged towards the end of follow-up. Late triers and decreasers also had similar alcohol use frequencies at the end of follow-up. Table 1 describes baseline characteristics of participants assigned to each of the seven trajectory groups.

In pairwise comparisons (see online supplemental table S4) of baseline characteristics, trajectory groups were best differentiated by drinking frequency and having friends who smoked. Sex and age differed among higher-risk trajectories (ie, early rapid escalators, steady drinkers, early frequent drinkers). Differences in novelty-seeking and impulsivity were observed between late triers and the other trajectory groups, and depressive symptoms differed between early frequent drinkers and the other trajectory groups.

Loss to follow-up was $<2 \%$ in all trajectory groups in cycles 1-20 (see online supplemental figure S1) and stable over time. Reasons for loss to follow-up included lack of

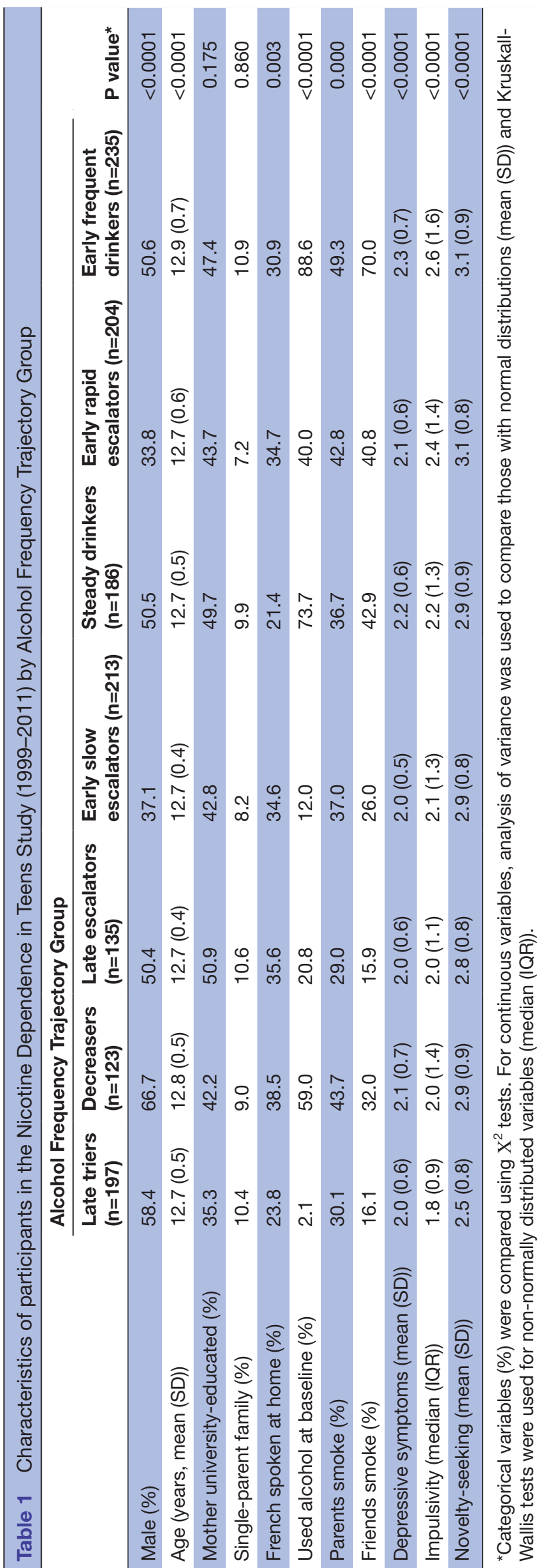


Table 2 Baseline characteristics of participants with and without binge drinking data in young adulthood, Nicotine Dependence in Teens Study (Canada, 1999-2005)

\begin{tabular}{lllc}
\hline & \multicolumn{2}{l}{ Binge drinking data } & P value \\
\cline { 2 - 3 } Characteristic & Yes (n=787) & No* $(\mathbf{n}=\mathbf{5 0 6})$ & 0.007 \\
\hline Male (\%) & 45.1 & 53 & $<0.001$ \\
Age (year, mean (SD)) & $12.7(0.5)$ & $12.9(0.6)$ & 0.026 \\
Mother university-educated (\%) & 46.7 & 38.5 & 0.16 \\
Single-parent family (\%) & 8.3 & 10.9 & 0.235 \\
French spoken at home (\%) & 33 & 27.6 & 0.087 \\
No. cigs/month (mean (SD)) & $7.2(47.7)$ & $13.8(73.5)$ & 0.018 \\
Used alcohol at baseline (\%) & 40.3 & 47.4 & 0.001 \\
Parents smoke (\%) & 35.2 & 44.6 & 0.01 \\
Friends smoke (\%) & 33.9 & 41.2 & 0.43 \\
Depressive symptoms (mean (SD)) & $2.1(0.6)$ & $2.1(0.7)$ & 0.105 \\
Impulsivity (mean (SD)) & $2.3(0.9)$ & $2.4(1.0)$ & 0.158 \\
\hline Novelty-seeking (mean (SD)) & $2.9(0.8)$ & $3.0(0.9)$ & \\
\hline
\end{tabular}

*Participants' missing data on binge drinking at either age 20 or 24 were excluded from the analyses.

time, lack of interest and moving to a non-participating high school. By age 24 (cycle 22), $81 \%$ of participants remained in the cohort. ${ }^{23}$ From ages 12 to 17 , relatively more early frequent drinkers were lost to follow-up. By age 17 , the probability of loss to follow-up was slightly higher among decreasers, steady drinkers, early rapid escalators and early frequent drinkers compared with other groups.

\section{Predicting binge drinking in young adulthood}

Of 1293 participants at baseline, $61 \%(\mathrm{n}=787)$ had data on binge drinking at both ages 20 and 24, and therefore comprised the analytical sample for these analyses. Compared with participants without binge drinking data in young adulthood $(n=506)$, participants in the analytical sample were 2.4 months younger on average, fewer were men (45\% vs 53\%) and more had universityeducated mothers. Fewer had used alcohol at baseline or had parents or friends who smoked (table 2).

Sustained binge drinking was reported by 260 participants $(33 \%)$. No estimated logistic model fit poorly (ie, all $p$ values for Hosmer-Lemeshow were $>0.1$ ). The prevalence of sustained binge drinking varied between $14 \%$ in late triers and 53\% in early frequent drinkers. Except for decreasers, members of all other trajectory groups were more likely to sustain binge drinking than late triers (table 3). Early frequent drinkers had a higher prevalence of sustained binge drinking and a markedly higher AOR $(53 \%$; AOR $(95 \% \mathrm{CI})=17.0(7.5,61.2))$ than late escalators $(27 \%$; AOR=3.5 $(1.4,10.0))$; the prevalence of binge drinking was similar across the remaining trajectories.

Compared with never drinkers at age 12, trying alcohol and drinking once or a couple of times per month were associated with higher odds of sustained binge drinking. Compared with never drinkers at age 17, weekly drinkers had the highest prevalence and AOR of sustained binge drinking ( $56 \%$; AOR=5.5 $(3.2,9.9)$ ), followed by monthly drinkers $(34 \%$; AOR=3.2 $(1.7,4.6))$, suggesting a doseresponse relationship that was not apparent at age 12 . Age at drinking onset was also related to sustained binge drinking: participants who began drinking before age 13 had higher odds than those who began between ages 13 and 15 or later than age 15 . Finally, adolescents who began drinking monthly or more often, regardless of age of onset, had higher odds of sustained binge drinking than never drinkers, although differences in prevalence and AORs were not as large as those for drinking onset. Results from the models using modal frequencies were consistent with those using frequency at age 12 or 17 .

Including trajectories in the model predicting sustained binge drinking increased predictive information by $60 \%$ over information provided by a model containing covariates only. Frequency of alcohol use at age 17 and drinking frequency in 11th grade increased predictive information by $57 \%$ and $59 \%$, respectively. The remaining alcohol use variables increased predictive information more modestly $(38 \%-48 \%)$.

Because any binge drinking carries risk, we conducted sensitivity analyses with any (ie, including less than monthly) versus no sustained binge drinking as the outcome. Results were substantively similar (see online supplemental table S5).

\section{DISCUSSION}

This is the first study to assess the associations between alternate measures of adolescent drinking and sustained binge drinking in young adulthood. It extends the usual drinker versus non-drinker comparison by comparing how informative trajectories of drinking frequency are relative to discrete time measures in identifying adolescents at 
Table 3 Unadjusted and adjusted* ORs (AORs) and 95\% Cls from logistic regression models of the association between adolescent drinking frequency and sustained binge drinking in young adulthood $(n=787)$, Nicotine Dependence in Teens (19992011)

\begin{tabular}{|c|c|c|c|c|c|c|}
\hline & & $\mathbf{N}$ & $\begin{array}{l}\text { Sustained binge } \\
\text { drinking† (\%) }\end{array}$ & OR (95\% Cl) & AOR (95\% Cl) & $\begin{array}{l}\text { Predictive } \\
\text { value } \neq\end{array}$ \\
\hline \multirow{7}{*}{$\begin{array}{l}\text { Drinking frequency } \\
\text { trajectory groups }\end{array}$} & Late triers & 121 & 14 & Ref & Ref & \multirow[t]{7}{*}{0.6} \\
\hline & Decreasers & 61 & 21.3 & $2.0(0.7-5.7)$ & $1.6(0.4-5.0)$ & \\
\hline & Late escalators & 96 & 27.1 & $3.4(1.5-9.2)$ & $3.5(1.4-10.0)$ & \\
\hline & Early slow escalators & 136 & 31.6 & $4.4(2.2-11.6)$ & $5.5(2.6-15.1)$ & \\
\hline & Steady drinkers & 109 & 35.8 & $5.1(2.4-13.4)$ & $5.8(2.7-16.8)$ & \\
\hline & Early rapid escalators & 123 & 35.8 & $5.7(2.7-15.0)$ & $7.5(3.4-23.2)$ & \\
\hline & Early frequent drinkers & 141 & 53.3 & $15.6(7.6-41.1)$ & $17.0(7.5-61.2)$ & \\
\hline \multirow{4}{*}{$\begin{array}{l}\text { Drinking frequency at } \\
\text { age } 12 \S\end{array}$} & Never & 449 & 24.9 & Ref & Ref & \multirow[t]{4}{*}{0.38} \\
\hline & A bit to try & 225 & 44 & $2.7(1.8-4.0)$ & $2.6(1.7-3.9)$ & \\
\hline & $1-2$ times a month & 63 & 46 & $3.0(1.5-6.1)$ & $2.8(1.3-6.1)$ & \\
\hline & Weeklyף & 15 & 46.7 & $3.2(0.6-7.3)$ & $2.2(0.4-12.8)$ & \\
\hline \multirow{4}{*}{$\begin{array}{l}\text { Drinking frequency at } \\
\text { age } 17 \S\end{array}$} & Never & 188 & 19.1 & Ref & Ref & \multirow[t]{4}{*}{0.57} \\
\hline & A bit to try & 56 & 14.3 & $0.6(0.2-1.4)$ & $0.6(0.2-1.5)$ & \\
\hline & $1-2$ times a month & 227 & 33.5 & $2.2(1.4-3.5)$ & $2.7(1.7-4.6)$ & \\
\hline & Weeklyq & 134 & 57.5 & $5.7(3.3-9.8)$ & $5.5(3.2-9.8)$ & \\
\hline \multirow[t]{4}{*}{ Age of drinking onset } & Never & 79 & 13.9 & Ref & Ref & \multirow[t]{4}{*}{0.39} \\
\hline & $<13$ years & 142 & 41.6 & $7.8(3.3-23.8)$ & $7.6(3.0-24.1)$ & \\
\hline & $13-15$ years & 281 & 31 & $4.5(1.8-13.7)$ & $4.9(1.9-15.7)$ & \\
\hline & $>15$ years & 86 & 23.3 & $3.3(1.2-10.9)$ & $3.2(1.1-11.0)$ & \\
\hline \multirow{4}{*}{$\begin{array}{l}\text { Age at onset of drinking } \\
\text { monthly or more often }\end{array}$} & Never & 158 & 18.4 & Ref & Ref & \multirow[t]{4}{*}{0.48} \\
\hline & $<13$ years & 127 & 44.9 & $8.3(3.9-19.0)$ & $8.2(3.7-19.6)$ & \\
\hline & $13-15$ years & 113 & 36.1 & $5.8(3.0-12.4)$ & $6.6(3.3-14.8)$ & \\
\hline & $>15$ years & 189 & 32.3 & $4.6(2.3-10.1)$ & $5.1(2.4-11.5)$ & \\
\hline \multicolumn{7}{|l|}{ Sensitivity analyses } \\
\hline \multirow{4}{*}{$\begin{array}{l}\text { Drinking frequency } 7 \text { th } \\
\text { gradet† }\end{array}$} & Never & 439 & 24.6 & Ref & Ref & \multirow[t]{4}{*}{0.41} \\
\hline & A bit to try & 186 & 40.9 & $2.3(1.5-3.4)$ & $2.3(1.5-3.6)$ & \\
\hline & $1-2$ times a month & 113 & 49.6 & $3.7(2.3-6.2)$ & $3.4(2.0-6.0)$ & \\
\hline & Weeklyq & 33 & 51.5 & $4.3(1.6-11.5)$ & $4.4(1.6-12.5)$ & \\
\hline \multirow{4}{*}{$\begin{array}{l}\text { Drinking frequency } \\
\text { 11th gradet† }\end{array}$} & Never & 181 & 17.7 & Ref & Ref & \multirow[t]{4}{*}{0.59} \\
\hline & A bit to try & 47 & 14.9 & $0.9(0.3-2.0)$ & $0.8(0.3-1.9)$ & \\
\hline & $1-2$ times a month & 260 & 32.3 & $2.3(1.5-3.8)$ & $3.2(1.9-5.4)$ & \\
\hline & Weeklyף & 149 & 56.4 & $6.7(4.0-11.5)$ & $7.5(4.4-13.3)$ & \\
\hline
\end{tabular}

*Adjusted for sex, mother university-educated, family status, language spoken at home, parent smoking and friends smoking at baseline. Because of missing values on covariates, 186 participants were excluded from adjusted analyses.

†Percentages are unadjusted.

$\ddagger$ The predictive value of each alcohol use variable represents the additional predictive information provided by the inclusion of the variable in the model compared with the information provided by a model containing covariates only. Likelihood ratio tests for all predictive value estimates were statistically significant at $p<0.001$.

§Drinking frequency was measured in cycle 1 at age 12 years on average, and cycle 20 at age 17 years on average.

ๆDue to the low number of participants endorsing the 'usually every day' response option, we collapsed this and the 'once or a couple of times a week' option into a 'weekly' category.

${ }^{* *}$ Drinking monthly or more often included participants who endorsed the 'once or a couple of times a month', 'once or a couple of times a week', or the 'usually every day' response options.

††Drinking frequency in each grade is represented by the participant's modal frequency over the four cycles in the grade (ie, cycles $1-4$ for 7 th grade; cycles $17-20$ for 11 th grade). 
risk of sustained binge drinking, a risk factor for alcohol dependence, in young adulthood. ${ }^{2122}$

Because of the high prevalence of alcohol use in adolescence, experts have advocated for universal preventive intervention before youth transition to work or higher education and/or screening to detect at-risk youth, enabling more efficient targeted intervention. However, although several screening tools exist (ie, AUDIT, AUDIT-C, single-questions), ${ }^{10}$ the USPSTF argues that there is insufficient evidence to identify the optimal timing for such screening during adolescence. Our findings coincide with reports that, between ages 12 and 15 , any drinking is associated with symptoms of alcohol-use disorders, ${ }^{20}$ and support that early screening for frequency of drinking is useful in identifying youth at risk of sustaining binge drinking as young adults.

The seven trajectories identified herein portray highly variable drinking frequency patterns during high school, although several converged in 11th grade. Five of the seven trajectory groups (ie, all except decreasers) were more likely than late triers to sustain at least monthly binge drinking into young adulthood, aligning with previous work showing a link between frequent alcohol use in adolescence and later alcohol-use disorders. ${ }^{11}$ Although trajectories relate to later binge drinking and were most informative in predicting sustained binge drinking, it takes years to determine an individual's trajectory group. Discrete time measures were also informative and have the added benefit of being substantially easier to assess in clinical or school settings. Drinking frequency at age 17 was marginally less informative than trajectory group membership, and drinking frequency at age 12,age at first drink, and transitioning to at least monthly drinking all had predictive value. Because asking how often an adolescent drinks is easy and because early preventive effort is likely more effective than later prevention, discrete time measures offer distinct advantages over trajectories.

Early drinking is associated with risky drinking and alcohol-use disorders in adulthood. In studies assessing drinking in early adolescence, age at onset was the strongest predictor of hazardous drinking at age 19 after controlling for risk factors associated with drinking onset. ${ }^{35}$ Furthermore, initiating drinking prior to age 14 was associated with more frequent drinking and binge drinking, as well as higher scores on two measures of problem drinking at ages 36 and $42 .^{36}$ Finally, in adults for whom age at first drink was assessed retrospectively, earlier onset drinking was strongly associated with hazardous drinking at the 3-year follow-up. ${ }^{37}$

We observed a dose-response between drinking frequency in adolescence and sustained binge drinking in young adulthood. However, $14 \%$ of late triers and $21 \%$ of decreasers later reported sustained binge drinking at least monthly. While early frequent alcohol use can identify at-risk youth, the normative nature of binge drinking in university and college ${ }^{3839}$ must be addressed. There is evidence that students with the most significant alcohol-related problems in adulthood are those who continue to binge drink frequently after university. ${ }^{40}$

\section{Strengths and limitations}

Strengths of our study include dense observations on alcohol use over more than a decade, use of inverse probability weighting to account for attrition in young adulthood, comparison of discrete time measures of drinking frequency with trajectories as predictors of sustained binge drinking and prospective assessment of age at onset.

Limitations include that many participants were lost to follow-up. However, adjustment for attrition in the trajectory analyses did not affect the shape or number of trajectories identified. Furthermore, inverse probability weighting accounted for missing binge drinking data. We lacked data on binge drinking in adolescence. However, because binge drinking is less useful than drinking frequency in identifying youth with alcohol problems, ${ }^{20}$ this should not affect the application of our results to intervention efforts. Finally, since $42 \%$ of participants had already consumed alcohol by age 12, our trajectories do not fully capture the natural course of alcohol use. Studies investigating drinking patterns in elementary schools are needed to fully characterise the natural course of alcohol consumption and identify early drinking patterns that necessitate intervention. ${ }^{10}$

\section{CONCLUSION}

Measures of age at onset and frequency of drinking before age 13 are useful in identifying youth at risk of sustained binge drinking as young adults. Since alcohol-use disorders are rare among adolescents aged $12-13$ years, ${ }^{20}$ identifying at-risk youth early may facilitate prevention of the onset of drinking-related problems.

\section{Author affiliations \\ ${ }^{1}$ School of Public Health, Université de Montréal, Montreal, Québec, Canada ${ }^{2}$ Research Centre, CHUM, Montreal, Québec, Canada \\ ${ }^{3}$ Department of Population and Quantitative Health Sciences, Division of Preventive and Behavioral Medicine, University of Massachusetts Medical School, Worcester, \\ Massachusetts, USA \\ ${ }^{4}$ Department of Psychiatry, Université de Montréal, Montreal, Québec, Canada}

Contributors M-PS designed the analytical plan, coordinated drafting the article, conducted parts of the data analysis and wrote sections of the article. RJW contributed to interpretation of the data and wrote sections of the updated article. MNA reviewed the literature, prepared the first draft of the manuscript and conducted some of the data analysis. DJ-A and GD contributed to the interpretation of data and edited sections of the article. JOL obtained the funding, developed the survey instruments, supervised data collection, contributed to interpretation of data and wrote sections of the article. All authors reviewed the article critically and participated in drafting the discussion, approved the final version, and are responsible for the reported research. M-PS and JOL had full access to all the data in the study and take responsibility for the integrity of the data and the accuracy of the data analysis.

Funding This work was supported by the Canadian Cancer Research Society (Grant \# 010271 and 017435). The funders were not involved in the design or conduct of the study; collection, management, analysis or interpretation of the data; or preparation, review or approval of the manuscript. M-PS is supported by a Chercheur-Boursier career award from the Fonds de Recherche du Quebec-Santé (FRQS). JOL holds a Canada Research Chair in the Early Determinants of Adult Chronic Disease. DJ-A holds a Clinical Scientist Career Award from the FRQS. 
MNA holds a Vanier Canada Graduate Scholarship from the Social Sciences and Humanities Research Council.

Competing interests None declared.

Patient and public involvement Patients and/or the public were not involved in the design, or conduct, or reporting, or dissemination plans of this research.

Patient consent for publication Not required.

Ethics approval The Ethics Review Committees of the Montréal Department of Public Health, the McGill University Faculty of Medicine and the Centre de Recherche du Centre Hospitalier de l'Université de Montréal approved the study.

Provenance and peer review Not commissioned; externally peer reviewed.

Data availability statement The data that support the findings are available from the corresponding author upon reasonable request. Access to NDIT data is open to university-appointed or affiliated investigators and to Masters, Doctoral and Postdoctoral students through their primary supervisor.

Open access This is an open access article distributed in accordance with the Creative Commons Attribution Non Commercial (CC BY-NC 4.0) license, which permits others to distribute, remix, adapt, build upon this work non-commercially, and license their derivative works on different terms, provided the original work is properly cited, appropriate credit is given, any changes made indicated, and the use is non-commercial. See: http://creativecommons.org/licenses/by-nc/4.0/.

ORCID iD

Marie-Pierre Sylvestre http://orcid.org/0000-0001-5803-4615

\section{REFERENCES}

1 McCambridge J, McAlaney J, Rowe R. Adult consequences of late adolescent alcohol consumption: a systematic review of cohort studies. PLoS Med 2011;8:e1000413.

2 Miech RA, Johnston LD, O'Malley PM. Monitoring the future national survey results on drug use 1975-2015: volume I, secondary school students, 2016.

3 Canadian Centre on Substance Use and Addiction. Canadian drug summary, 2017. Available: www.cpha.ca/sites/default/files/uploads/ resources/cannabis/ccsa-canadian-drug-summary-cannabis-2017en.pdf [Accessed 29 Nov 2018].

4 Wellman RJ, Vaughn JA, Sylvestre M-P, et al. Relationships between current and past binge drinking and systolic blood pressure in young adults. J Adolesc Health 2016;58:352-7.

5 Labhart F, Livingston M, Engels R, et al. After how many drinks does someone experience acute consequences-determining thresholds for binge drinking based on two event-level studies. Addiction 2018;113:2235-44.

6 Siqueira L, Smith VC. Committee on substance abuse binge drinking. Pediatrics 2015;136:e718-26.

7 Tripodi SJ, Bender K, Litschge C, et al. Interventions for reducing adolescent alcohol abuse: a meta-analytic review. Arch Pediatr Adolesc Med 2010;164:85-91.

8 Tanner-Smith EE, Lipsey MW. Brief alcohol interventions for adolescents and young adults: a systematic review and metaanalysis. J Subst Abuse Treat 2015;51:1-18.

9 Moyer VA, Preventive Services Task Force. Screening and behavioral counseling interventions in primary care to reduce alcohol misuse: U.S. preventive services Task force recommendation statement. Ann Intern Med 2013;159:210-8.

10 D'Amico EJ, Parast L, Meredith LS, et al. Screening in primary care: what is the best way to identify at-risk youth for substance use? Pediatrics 2016;138

11 Nelson SE, Van Ryzin MJ, Dishion TJ. Alcohol, marijuana, and tobacco use trajectories from age 12 to 24 years: demographic correlates and young adult substance use problems. Dev Psychopathol 2015;27:253-77.

12 Schulenberg J, O’Malley PM, Bachman JG, et al. Getting drunk and growing up: trajectories of frequent binge drinking during the transition to young adulthood. J Stud Alcohol 1996;57:289-304.

13 Schulenberg J, Wadsworth KN, O’Malley PM. Adolescent risk factors for binge drinking during the transition to young adulthood: variableand pattern-centered approaches to change, 1997.

14 Chassin L, Pitts SC, Prost J. Binge drinking trajectories from adolescence to emerging adulthood in a high-risk sample: predictors and substance abuse outcomes. J Consult Clin Psychol 2002;70:67-78.
15 Oesterle S, Hill KG, Hawkins JD, et al. Adolescent heavy episodic drinking trajectories and health in young adulthood. J Stud Alcohol 2004;65:204-12.

16 Tucker JS, Ellickson PL, Orlando M, et al. Substance use trajectories from early adolescence to emerging adulthood: a comparison of smoking, binge drinking, and marijuana use. J Drug Issues 2005;35:307-32.

17 Smit K, Voogt C, Hiemstra M, et al. Development of alcohol expectancies and early alcohol use in children and adolescents: a systematic review. Clin Psychol Rev 2018;60:136-46.

18 Sher KJ, Jackson KM, Steinley D. Alcohol use trajectories and the ubiquitous cat's cradle: cause for concern? J Abnorm Psychol 2011;120:322-35.

19 Vachon DD, Krueger RF, Irons DE, et al. Are alcohol trajectories a useful way of identifying at-risk youth? A multiwave LongitudinalEpidemiologic study. J Am Acad Child Adolesc Psychiatry 2017;56:498-505.

20 Chung T, Smith GT, Donovan JE, et al. Drinking frequency as a brief screen for adolescent alcohol problems. Pediatrics 2012;129:205-12.

21 Sloan F, Grossman D, Platt A. Heavy episodic drinking in early adulthood and outcomes in midlife. J Stud Alcohol Drugs 2011;72:459-70.

22 Tavolacci M-P, Berthon Q, Cerasuolo D, et al. Does binge drinking between the age of 18 and 25 years predict alcohol dependence in adulthood? A retrospective case-control study in France. BMJ Open 2019;9:e026375.

23 O'Loughlin J, Dugas EN, Brunet J, et al. Cohort profile: the nicotine dependence in teens (NDIT) study. Int J Epidemiol 2015;44:1537-46.

24 Paradis G, Lambert M, O'Loughlin J, et al. The Québec child and adolescent health and social survey: design and methods of a cardiovascular risk factor survey for youth. Can J Cardiol 2003;19:523-31.

25 Adlaf E, Begin P ES. Canadian addiction survey (CAS): A national survey of Canadians' use of alcohol and other drugs: prevalence of use and related harms: detailed report. Canadian Centre on Substance Abuse: Ottawa, 2005. http://www.ccsa.ca/2005\% 20CCSA\%20Documents/ccsa-004028-2005.pdf

26 SAMHSA. Substance abuse and mental health service administration, 2014. Available: http://www.samhsa.gov/atod/ tobacco [Accessed 13 Aug 2015].

27 Jones BL, Nagin DS, Roeder K. A SAS procedure based on mixture models for estimating developmental trajectories. Sociol Methods Res 2001;29:374-93.

28 Haviland AM, Jones BL, Nagin DS. Group-based trajectory modeling extended to account for nonrandom participant attrition. Sociol Methods Res 2011;40:367-90.

29 Hayatbakhsh MR, Mamun AA, Najman JM, et al. Early childhood predictors of early substance use and substance use disorders: prospective study. Aust N Z J Psychiatry 2008;42:720-31.

30 Leung RK, Toumbourou JW, Hemphill SA. The effect of peer influence and selection processes on adolescent alcohol use: a systematic review of longitudinal studies. Health Psychol Rev 2014;8:426-57.

31 Statistics Canada. Heavy drinking, 2016. Available: https://www150. statcan.gc.ca/n1/pub/82-229-x/2009001/deter/hdx-eng.htm [Accessed 29 Mar 2020].

32 Vermunt JK. Latent class modeling with covariates: two improved three-step approaches. Polit Anal 2010;18:450-69.

33 Harrell FE. Statistically efficient ways to quantify added predictive value of new measurements, 2019. Available: https://www.fharrell. com/post/addvalue/ [Accessed 19 Jun 2020].

34 Harrell FE. Regression modeling strategies: with applications to linear models, logistic regression, and survival analysis. Springer, 2001.

35 Buchmann AF, Schmid B, Blomeyer D, et al. Impact of age at first drink on vulnerability to alcohol-related problems: testing the marker hypothesis in a prospective study of young adults. J Psychiatr Res 2009;43:1205-12.

36 Pitkänen T, Lyyra A-L, Pulkkinen L. Age of onset of drinking and the use of alcohol in adulthood: a follow-up study from age 8-42 for females and males. Addiction 2005;100:652-61.

37 Dawson DA, Goldstein RB, Chou SP, et al. Age at first drink and the first incidence of adult-onset DSM-IV alcohol use disorders. Alcohol Clin Exp Res 2008;32:2149-60.

38 O'Malley PM, Johnston LD. Epidemiology of alcohol and other drug use among American college students. J Stud Alcohol Suppl 2002;14:23-39.

39 Neighbors C, Dillard AJ, Lewis MA, et al. Normative misperceptions and temporal precedence of perceived norms and drinking. J Stud Alcohol 2006;67:290-9.

40 Ham LS, Hope DA. College students and problematic drinking: a review of the literature. Clin Psychol Rev 2003;23:719-59. 